\title{
Ellipsis AND THE STRUCTURE OF DiscourSE
}

\author{
Daniel Hardt \\ Copenhagen Business School \\ Maribel Romero \\ University of Pennsylvania
}

\begin{abstract}
It is generally assumed that ellipsis requires certain parallelism between the clause containing the ellips is and some antecedent clause. We argue that the parallelism requirement generated by ellipsis must be applied in accordance with discourse structure: a matching antecedent clause must be found that locally c-commands the clause containing the ellipsis in the discourse tree. We show that the claim makes several correct predictions concerning the interpretation of ellipsis, both in terms of the selection of the antecedent (in Sluicing and Verb Phrase Ellipsis), and in terms of the possible readings given a particular antecedent (in the "many-clause" puzzle and in Antecedent-Contained Deletion).
\end{abstract}

\section{Introduction}

Many authors have suggested that ellipsis and other processes of reduction require a certain similarity or parallelism between the reduced clause and some antecedent clause in discourse. It has also frequently been proposed that discourse structure is relevant to interpretation of ellipsis and related constructions. In this paper, we combine these two claims, and propose that the parallelism requirement is strongly constrained by discourse structure. We assume the following two background claims:

Matching Condition on Ellipsis Resolution: Ellipsis resolution requires that a matching relation holds between a containing clause $\mathrm{E}$ and some antecedent clause A. (Dalrymple et al., 1991; Rooth, 1992a; Tancredi, 1992; Fiengo and May, 1994; Schwarzschild, 1999)

Discourse Structure: Clauses in a discourse are structured according to discourse relations; ellipsis resolution (and other anaphora resolution) occurs as a side-effect of establishing discourse relations. (Hobbs, 1979; Asher, 1993; Prust et al., 1994; Kehler, 2000; Asher et al., 2001; Webber et al., 2001)

The central claim of this paper is the following:

Discourse Condition on Ellipsis Resolution: Clause A can be antecedent for ellipsis in clause E iff A locally c-commands E in discourse tree. ${ }^{1}$

In what follows, we show that this claim makes a variety of correct predictions concerning the interpretation of ellipsis, both in terms of the selection of the antecedent, and in terms of the possible readings given a particular antecedent. The paper is organized as follows. In section 2 , we present our background claims concerning ellipsis resolution and discourse structure in

\footnotetext{
${ }^{1}$ We define local c-command as follows: A locally c-commands $\mathrm{E}$ iff $\mathrm{A}$ c-commands $\mathrm{E}$ and there is no $\mathrm{C} \mathrm{c}-$ commanding $\mathrm{E}$ that appears between $\mathrm{A}$ and $\mathrm{E}$. In most cases, the locally c-commanding A-clause is also sister to E. In fact, in this paper, it is only the many-clause puzzle (example (48)) for which we require local c-command instead of sisterhood. In future work, we will investigate the question of whether the local c-command requirement can be replaced with a sisterhood requirement. For the purposes of the present paper, we will use the expressions "A locally c-commands E" and "A is the sister of E" to indicate that the Discourse Condition is satisfied.
} 
somewhat more detail. Section 3 concerns antecedent selection: using both sluicing and VPellipsis (VPE), we show how the proposed Discourse Condition uses discourse structure to rule out antecedents that would otherwise be incorrectly permitted. We also show that, while the Discourse Condition does place much stronger constraints than previous approaches, it is not quite as restrictive as one might think, since matching may often be performed at different levels and it is sensitive to implicit material and to contextual inferencing. In sections 4 and 5, we examine the issue of possible readings for ellipsis occurrences, focusing on two versions of the "many-clause" puzzle for VPE in section 4 and on scope readings for Antecedent-Contained Deletion (ACD) in section 5. We show that our claim rules out (section 4) or ranks lower (section 5) readings that are incorrectly permitted by theories that do not refer to discourse structure. Finally, in section 6, we discuss some potential problems for the approach involving symmetric focus, and we draw some conclusions.

\section{Background}

\subsection{Ellipsis Resolution as Matching}

(Rooth, 1992a) argues that ellipsis involves a matching relation that is not necessarily restricted to the minimal clause containing the ellipsis. (See also (Dalrymple et al., 1991; Tancredi, 1992; Fiengo and May, 1994; Schwarzschild, 1999) among many others). In this paper, we will assume Rooth's (1992) formalization of this idea, which he applies to ellipsis (complete phonological reduction) as well as to deaccenting (a milder form of phonological reduction). ${ }^{2}$

(Rooth, 1985) defines the focus value of an expression $\alpha$ as the set of denotations constructed as follows:

(4) a. If $\alpha$ is a non-focused lexical item, then $\mathrm{F}(\alpha)=\{\alpha\}$.

b. If $\alpha$ is a focused lexical item, then $\mathrm{F}(\alpha)=D_{\sigma}$, where $\sigma$ is the type of $\alpha$.

c. If the node $\alpha$ has the daughters $\beta$ and $\gamma$ (order irrelevant), and there are types $\sigma$ and $\tau$ such that $\langle\sigma, \tau\rangle$ is the type of $\beta$ and $\sigma$ is the type of $\gamma$, then $\mathrm{F}(\alpha)=\{x \in$ $\left.D_{\tau}: \exists y, z[y \in F(\beta) \wedge z \in F(\gamma) \wedge x=y(z)]\right\}$

Thus the focus value of $P$ is the set of expressions that result from replacing every focused element $e$ in $P$ with some element of the same semantic type as $e$. Applying the above condition to ellipsis, (Rooth, 1992a) states the following Matching Condition:

\section{Matching Condition:}

Ellipsis requires that there be some phrase E containing the ellipsis and some antecedent phrase $\mathrm{A}$ in the discourse, such that $\llbracket A \rrbracket$ is or contextually implies a member of $\mathrm{F}(E)$.

Consider the following example:

Susan arrived late last night, and KAREN did, too.

$\left[[\text { S Susan arrived late last night }]_{S 1} \rrbracket \in \mathrm{F}\left([\text { KAREN did arrive late last night }]_{S 2}\right)\right.$

The ellipsis is licensed, with the reading "Karen arrived late last night", since the focus value of E is the following set of propositions:

\footnotetext{
${ }^{2}$ We follow Rooth in assuming that our account applies to deaccenting the same way as it does to ellipsis, although in this paper we will concentrate on ellipsis examples as opposed to deaccenting.
} 
$\{P \mid \exists x . P=x$ arrived late last night $\}$

The antecedent proposition denoted by Susan arrived late last night is clearly an element of this set. $^{3}$

\subsection{Sloppy Identity as Matching}

Rooth's matching condition is stated independently of the issue of sloppy identity, which is illustrated by the following example:

(9) $\mathrm{John}_{1}$ revised his 1 paper. Bill $\mathrm{did}_{2}$ too (revised his 2 paper)

There are many well-known mechanisms to permit sloppy readings, many of which are consistent with Rooth's condition. Perhaps the simplest is to assume that NP's in general can raise, being adjoined to a lambda abstract, as follows (see e.g. (Heim and Kratzer, 1998)):

$[X P] \Rightarrow\left[N P X P^{\prime}\right]$, where $X P^{\prime}=\lambda x \cdot X P[N P / x]$

A pronoun can then be coindexed with the variable bound by the lambda operator. Thus if we raise Bill in (9) and coindex the pronoun his with the lambda bound variable, the sloppy reading is permitted.

(10) $\mathrm{John}_{1}$ revised his 1 paper. [Bill $\lambda x . x$ revised $x$ 's paper]

Now the focus value of the ellipsis phrase $\mathrm{E}$ is

$\{P \mid \exists x . P=x$ revised $x$ 's paper $\}$

The denotation of the antecedent phrase A John 1 revised his ${ }_{1}$ paper is clearly a member of this set. This set can be abbreviated as follows:

$\{x$ revised $x$ 's paper $\}$

This is the set of all propositions in which some individual is substituted for $x$ in " $x$ revised $x$ 's paper". In this paper, we will use such abbreviations for alternative sets.

\subsection{Matching and Inference}

(Rooth, 1992a) notes that ellipsis sometimes is licensed where A is not an element of the focus value of E. He suggests that inferences can sometimes apply. Note that the Matching Condition above states that $[[A \rrbracket$ is or contextually implies a member of $\mathrm{F}(E)$. The following examples illustrates this:

\footnotetext{
${ }^{3}$ As a special case, ellipsis across question and answer is governed by the general matching condition independent of ellipsis- that (Rooth, 1992b) proposes for Question/Answer pairs. This condition is given in 7 and illustrated below:
}

(7) Matching Condition for Q/A pairs:

Given a question answer sequence $\mathrm{Q} \mathrm{A}, \llbracket Q \rrbracket$ must be a subset of $\mathrm{F}(\mathrm{A})$.

(8) Q: [Which student called? $]_{S 1}$

A: [JOHN (called) $)_{s 2}$.

[[ [Which student called? $\left.\left.]_{S 1}\right]\right]=\{\mathrm{x}$ called: $\mathrm{x}$ is a student $\}$

$\left.\left.[\text { [Which student called? }]_{S 1}\right]\right] \subset \mathrm{F}\left(\left[\mathrm{JOHN}(\text { called })_{s 2}\right)=\{\mathrm{x}\right.$ called': $\mathrm{x}$ is an individual $\}$. 
(11) People convinced John to play the lottery, and then SUE decided to as well.

[People convinced John to play the lottery $]_{S 1}$ implies [John decided to play the lottery].

$\left[\mathrm{John}_{\mathrm{N}}\right.$ decided to play the lottery $] \in \mathrm{F}\left([\mathrm{SUE} \text { decided to play the lottery }]_{S 2}\right)$

It is clearly necessary to constrain inference in the licensing of ellipsis, but we will not attempt this here, leaving this as an open question for future research. We merely note that inference sometimes allows ellipsis that otherwise would violate the matching condition.

Finally, we point out that Rooth and other authors propose that an extra identity condition applies to ellipsis but not to deaccenting: the elided constituent itself has to find an antecedent in the discourse to which it is identical (syntactically identical, as in (Rooth, 1992a; Fiengo and May, 1994), or semantically identical, as in (Hardt, 1993; Jacobson, 1992); see also (Merchant, 2001) for a variant of the semantic identity approach.) We will not address this extra condition in the present paper; however, we observe that an ellipsis clause must (generally) have an overt $\mathrm{VP}$ antecedent. In determining clauses $\mathrm{E}$ and $\mathrm{A}$ to satisfy the matching requirement, we note that clause A must contain the overt VP antecedent, and may not contain the VPE.

\subsection{Discourse Relations}

There is an extensive literature concerning the structure arising from clausal discourse relations (Hobbs, 1979; Mann and Thompson, 1986; Asher, 1993; Marcu, 2000; Webber et al., 2001). While there is still controversy concerning the proper inventory of discourse relations, and the class of possible resulting structures, much progress has been made, and there is substantial agreement concerning standard relations such as the following:

- Temporal: A before/after B

- Cause-Effect/Subordination: A because B A although $B$

- Parallel: A and B too

- Contrast: A but not $B$

- Constructions: if $A$ then $B$

We will restrict ourselves to relatively uncontroversial structures where relations such as the above are explicitly signalled with discourse particles. We will also follow the fairly standard view that discourse relations (both explicit and implicit) give rise to a tree structure (Asher, 1993; Prust et al., 1994) (but see (Webber et al., 2001) for a critical examination of the tree structure assumption).

\section{Selection of Antecedent}

The Discourse Condition makes clear predictions concerning the selection of antecedent in ellipsis resolution. The goal of this section is to examine these predictions. We begin with simple examples of sluicing, in 3.1, followed by simple examples of VP ellipsis in 3.2. In both cases, we show that the Discourse Condition plays an essential role in correctly accounting for the facts. In the three following subsections, we examine more complex examples where indepedently motivated aspects of semantic interpretation and focus matching need to be invoked. Subsection 3.3 concentrates on examples of VP ellipsis where matching and the Discourse Condition apply at 
a higher level, between non-minimal clauses containing the elided VP and the antecedent VP. This flexibility is already present in Rooth's original matching proposal. Subsection 3.4 tackles cases which involve implicit material independently required for the interpretation of modal operators. Finally, in subsection 3.5, we examine cases where some simple inferences are required to produce the correct matching. The appeal to inference and contextual implicatures is part of Rooth's matching approach, independently of the new Discourse Condition.

\subsection{Sluicing}

Ross (1969) coined the term "Sluicing" to refer to the ellipsis of IP in an interrogative clause, as exemplified in (12)-(13). (Chung et al., 1995) noted that the expression in the ANT clause corresponding to the sluiced $w h$-phrase is often an indefinite, explicit in (12) and implicit in (13). Let us call this corresponding expression the "correlate".

John called somebody. I wonder who.

(Romero, 1998) gives a Matching Condition account of the relation between a sluiced $w h$-phrase and the shape of its correlate. She exploits the fact that sluiced wh-phrases -like remnants of ellipsis in general- bear focus stress, and she defines a set of alternatives of a focused $w h$ Determiner that includes an existential option. The result is, roughly, that $S_{1}$ matches $S_{2}$ in e.g. (13) as follows:

(14) $\quad[\text { John ate }]_{S 1}$. But it's unclear [WHAT (he ate) $]_{S 2}$.

$\left[\left[[\exists \mathrm{x}: \text { John ate } \mathrm{x}]_{S 1} \rrbracket \in \mathrm{F}\left([\text { WHAT } \mathrm{x} \text { : he ate } \mathrm{x}]_{S 2}\right)\right.\right.$

Furthermore, (Romero, 1998) argues that uttering a sentence like John ate implies that the speaker has some propositional attitude towards the proposition expressed. That is, uttering John ate implies I believe / I know / It is clear that John ate. Once this is taken into account, matching obtains between $S_{1}$ and $S_{3}$, that is, between two direct sisters in the discourse tree: ${ }^{4}$

$\left[\mathrm{John}_{\text {ate }}\right]_{S 1}$. But [ it's unclear [WHAT (he ate) $\left.]_{S 2}\right]_{S 3}$.

$[\exists \mathrm{x} \text { : John ate } \mathrm{x}]_{S 1}$ implies the proposition "It is clear that $\exists \mathrm{x}$ : John ate $\mathrm{x}$ ", and

"It is clear that $\exists \mathrm{x}$ : John ate $\mathrm{x} " \in \mathrm{F}\left([\mathrm{It} \text { is UNCLEAR WHAT } \mathrm{x} \text { : he ate } \mathrm{x}]_{S 3}\right)$

For the sake of simplicity, we will ignore these propositional attitudes in the next examples. We will concentrate on finding an A-clause for the sluiced interrogative, assuming that, once it is found, the necessary propositional attitude will be implied by the context.

Let us now turn to the following example, which (Chung et al., 1995) observe is ill-formed:

$\left.*[\text { Agnes arrived after [John ate }]_{S 3}\right]_{S 1}$, but [it's unclear what $]_{S 2}$.

\footnotetext{
${ }^{4}$ Romero's actual focus value for $\mathrm{S}_{2}$, given in (15), includes an existential interrogative (with whether) rather than an existential declarative. Thus, the corresponding matching is done as is (16) rather than as in the simplified version given in the text. This difference is immaterial to the argument in the present paper.

(15) $\quad$ F(WHAT John ate $)=$ \{what $\mathrm{x}$ : John ate $\mathrm{x}$, how many $\mathrm{x}$ : John ate $\mathrm{x}$, whether $\exists \mathrm{x}$ : John ate $\mathrm{x}\}$

(16) $\quad[\text { John ate }]_{S 1}$. But $\left[\text { it's unclear }[\text { WHAT (he ate) }]_{S 2}\right]_{S 3}$. Uttering [ $\exists \mathrm{x}$ : John ate $\mathrm{x}]_{S 1}$ implies the proposition "It is clear whether (or not) $\exists \mathrm{x}$ : John ate $\mathrm{x}$ ", and "It is clear whether (or not) $\exists x$ : John ate $\mathrm{x}$ " $\in \mathrm{F}\left([\mathrm{It} \text { is UNCLEAR WHAT } \mathrm{x} \text { : he ate } \mathrm{x}]_{S 3}\right.$ )
} 
(Chung et al., 1995) claim that unacceptability results from an island constraint, as with the overt counterpart in (20):

(19) $*$ [Agnes arrived after [John ate $\left.{ }_{S 3}\right]_{S 1}$, but [it's unclear what (Agnes arrived after John ate $\mathrm{t})]_{S 2}$.

(20) *It's unclear what Agnes arrived after John ate t.

However, (Chung et al., 1995) do not consider the possibility of the reading in (21), whose overt (non-deaccented) counterpart (21) has no island violation and is perfectly fine:

(21) *[Agnes arrived after [John ate $\left.]_{S 3}\right]_{S 1}$, but [it's unclear what (John ate) $]_{S 2}$.

(22) Agnes arrived after John ate, but it's unclear what John ate.

Nothing in (Chung et al., 1995)'s theory (or other theories of ellipsis) rules representation (21) out. In the present account, (21) is ungrammatical because no matching antecedent is found that is in the right discourse relation, since:

i. $S_{3}$ matches $S_{2}$, but $S_{3}$ does not c-command $S_{2}$ in the discourse tree, and

ii. $S 1$ c-commands $S_{2}$ in the discourse tree, but $S_{1}$ and $S_{2}$ do not match. That is, [[ [Agnes arrived after John ate $]_{S 1} \rrbracket \notin$ F[WHAT x: John ate $\left.\mathrm{x}\right]_{S 2}$

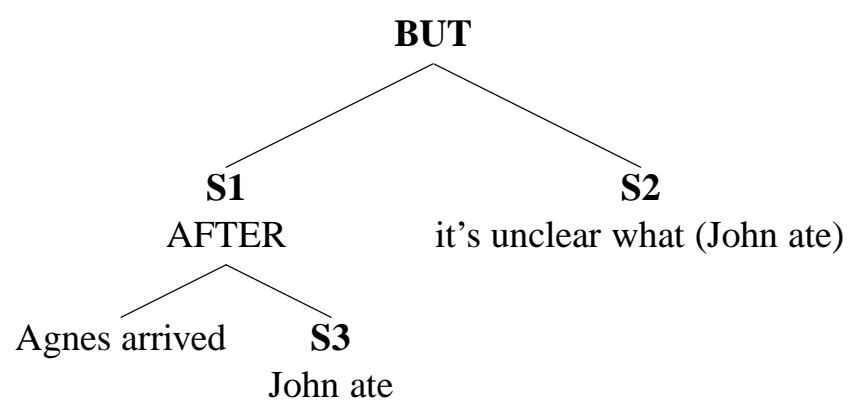

Example (21)

If we change the discourse structure, as in (23), the example becomes acceptable.

Agnes arrived while [[John was eating $]_{S 1}$ and [I was trying to figure out what $\left.]_{S 2}\right]$.

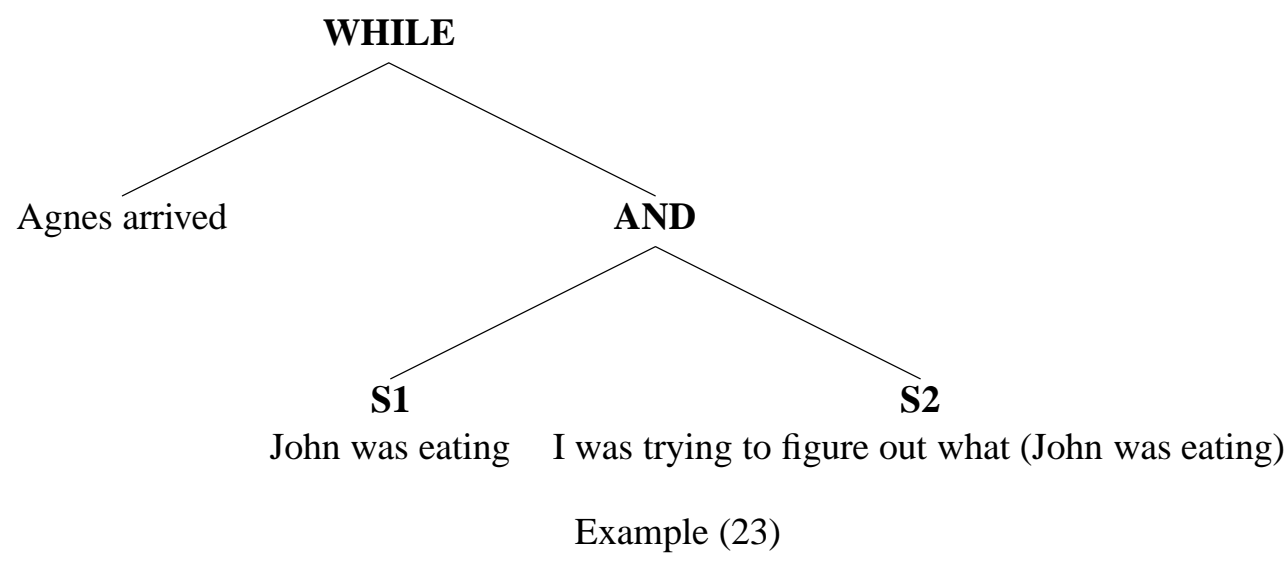

The sentence is grammatical because the Matching Condition and the Discourse Condition are now both met. $S_{1}$ matches $S_{2}$ in (23), as sketched in (24). And, given that $S_{1}$ is sister to $S_{2}, S_{1}$ is permitted as antecedent to the sluice by the Discourse Condition. 
$[[[\exists \mathrm{x}$ : John was eating $\mathrm{x}] \rrbracket \in \mathrm{F}$ ((I was trying to figure out) WHAT $\mathrm{x}$ : John was eating $\mathrm{x}]$ )

\subsection{VP Ellipsis}

We have seen that discourse structure correctly rules out potential antecedents for sluicing. In this section, we will see that the same is true of VP ellipsis. Take, for example, (25). Here, the ellipsis site can be resolved to the VP arrive after John ate, but not to the embedded VP ate.

[Agnes arrived after [John ate.] $\left.{ }_{S 3}\right]_{S 1}$ (But) [Bill didn’t*(eat)/ (arrive after John ate) ]$_{S 2}$.

According to our analysis, in (25), $S_{2}$ cannot take $S_{3}$ as its matching A-clause because $S_{3}$ does not c-command $S_{2}$, as shown in the discourse tree below. Hence, the ellipsis site cannot be resolved to the VP of $S_{3}$. Instead, $S_{2}$ is allowed to match its discourse sister $S_{1}$, and thus the ellipsis is resolved to $\mathrm{S}_{1}$ 's VP arrive after John ate. ${ }^{5}$

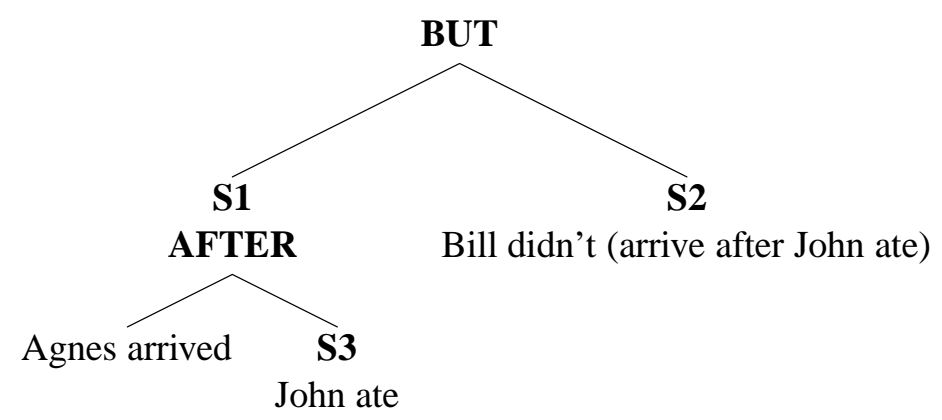

The same discourse configuration obtains if, instead of being juxtaposed, the larger clauses $S_{1}$ and $S_{2}$ are placed in an if-then discourse structure. Given the resulting discourse tree under (27), only $S_{1}$ is a possible A-clause for $S_{2}$ according to the Discourse Condition. ${ }^{6}$

(27) If [Agnes arrived after [John ate $\left.]_{S 3}\right]_{S 1}$ then [Bill didn't *(eat)/ (arrive after John ate) ]$_{S 2}$.

We analyze Antecedent Contained Deletion (ACD) sentences like (28) in a similar fashion. That is, even though relative clauses -like if-clauses- are syntactically embedded within the matrix $\mathrm{CP}$ projected by $\mathrm{S}_{2}$, the discourse relation is established between the relative clause IP and a

\footnotetext{
${ }^{5}$ Note that ellipsis resolution to eat is impossible even in contexts where the overt (non-deaccented) counterpart would be fine, as shown in (26):

(26) Context: $\mathrm{S}$ works at a day care with three babies, John, Bill and Jesse, each of which has some problem. John only has a good digestion when Agnes feeds him. Bill sometimes refuses to eat. Jesse is a loud cryer.

A: How was your day at work?

S: A nightmare!!! Lots of things went wrong. Agnes arrived after John ate. \# Bill didn't (eat). Jesse cried for three hours...

S': A nightmare!!! Agnes arrives after John ate. Bill didn't eat. Jesse cried for three hours...
}

${ }^{6}$ See subsection 6 for an elaboration on (27) involving symmetric focus. 


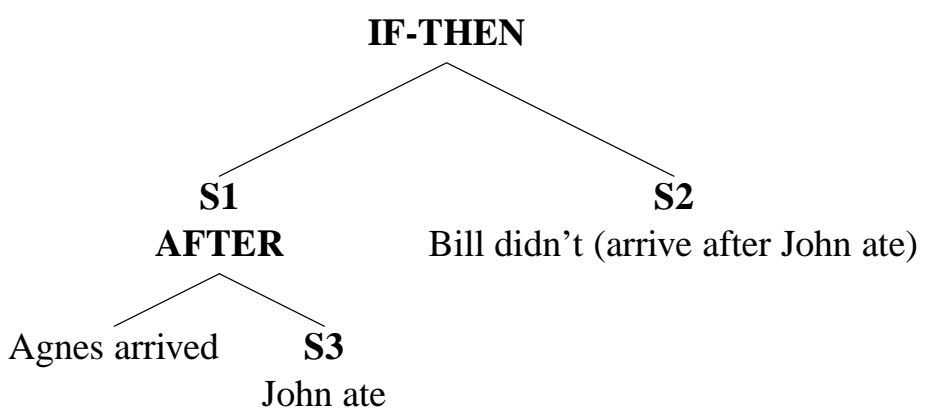

matrix IP node excluding the relative clause. The resulting discourse tree is given below. Again, local c-command determines that the ellipsis should be resolved to arrive after John ate. ${ }^{7}$

(28) Everyone who [could have arrived after John ate $]_{S 1}[\mathrm{did} *($ ate $) /($ arrive after $\mathrm{J}$ ate) ]$_{S 2}$

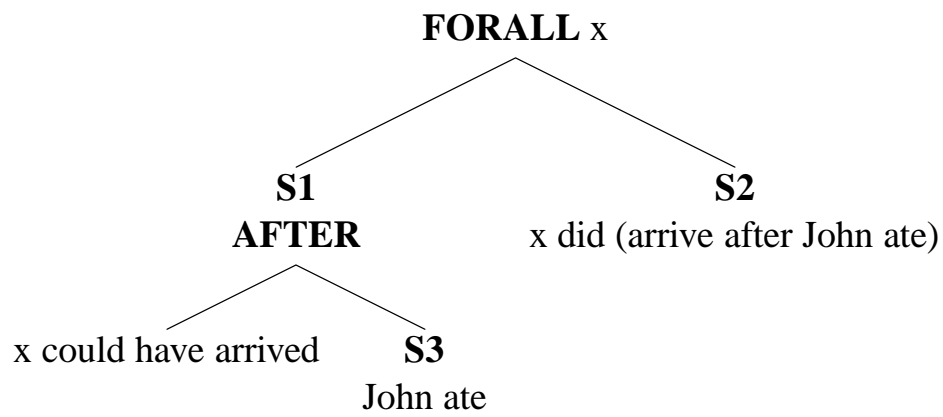

\subsection{Matching at Different Levels}

The c-command constraint sharply limits possible interpretations for ellipsis, in a way that might at first glance appear excessively restrictive. For example, one might think that embedded antecedents are never possible, since they cannot c-command the ellipsis site. It is important to realize however, that the matching can often take place at many levels. Recall that Rooth's Matching Condition simply requires matching between some antecedent constituent A and some constituent E containing the ellipsis; in particular, Rooth's condition does not require that the minimal containing clauses match. We will see that, in all of the following cases, apparent matching between clauses without local c-command is due to matching clauses at a higher level that are in the appropriate c-command relation.

We start with the set of examples (29)-(31). (29) is like the examples from the section 3.2. The relative clause $S_{1}$ and the main clause $S_{2}$ are discourse sisters in a ForAll structure. Hence matching can apply between them and the ellipsis is resolved to $\mathrm{S}_{1}$ 's VP.

(29) Everyone who [ wanted to leave before he ate salmon] $]_{S 1}$ [did *(eat salmon) / (leave before he ate salmon) $]_{S 2}{ }^{8}$

(30) $[\text { The man who [ate salmon }]_{S 3}$ left this evening $]_{S 1}$. [The man who [ didn't(eat salmon) $]_{S 4}$, left this afternoon. $]_{S 2}$

(31) [The man who ate salmon left this evening $]_{S 1}$, and [John did too (leave this evening)/*(eat salmon). $]_{S 2}$

\footnotetext{
${ }^{7}$ See section 5 for further elaboration on ACD.

${ }^{8}$ Note that the ellipsis can be leave before he ate the salmon, excluding want. See section 5 on this issue.
} 
But what about (30)? Despite the fact that the two embedded clauses $S_{3}$ and $S_{4}$ in (30) are not discourse sisters, ellipsis resolution can select the embedded VP in $\mathrm{S}_{3}$. We propose that here matching is performed not between $S_{3}$ and $S_{4}$, but between the two matrix clauses $S_{1}$ and $S_{2}$, which are discourse sisters. This can be seen by comparing (30) with (31). (31) shows that, if we change the second matrix sentence so that the matrix sentences $S_{1}$ and $S_{2}$ do not match, the embedded VP eat salmon is not an available antecedent anymore.

A second type of example, which involves questions, is given in (32). Here the local ccommander $\mathrm{S}_{2}$ does not provide the antecedent for the VP ellipsis site. But, again, our ccommand constraint is not violated, since matching can be done between the question $S_{1}$ and the entire sentence $S_{4}$, which stand in the Question/Answer discourse relation with $S_{1}$ :

[Did the students answer the survey? $]_{S 1}$

$\left[\text { Everyone who }[\text { received the forms }]_{S 2}[\mathrm{did}]_{S 3} \text { (answer the survey) }\right]_{S 4}$

In this sense, matching in (32) obtains exactly at the same level as in (33), between a question and its sister answer.

[Did the students answer the survey? $]_{S 1}$

Yes, [they did (answer the survey) $]_{S 4}$

The only difference is that, while (33) provides a complete answer, (32) only gives a partial one. Following Groenendijk-Stokhof (1984), a partial answer eliminates some equivalence class in the partition (of possible exhaustive answers) induced by the question, but it does not eliminate all but one. Or, in terms of (Büring, 1997), $\mathrm{S}_{4}$ in (32) answers some subquestion of the relevant question, but leaves some other subquestions unanswered. ${ }^{9}$

\subsection{Implicit Material}

Consider example (37). Here, $S_{1}$ seems to match $S_{2}$ and resolve the VPE with it, despite the lack of local c-command between them:

$\left.[\text { If it rains, [ John will come home }]_{S 1}\right]_{S 0}$. [ Peter might (come home) $]_{S 2}$, too.

However, note that modals always carry some restrictor set $\mathrm{C}$ of possible worlds. This set is at least partly determined contextually, and it can be further restricted with an explicit if-clause (Kratzer, 1979; von Fintel, 1994). In (37), the restrictor set is specified by the if-clause for $\mathrm{S}_{0}$ and contextually determined for $\mathrm{S}_{2}$. But note that the restrictor of might in $\mathrm{S}_{2}$ is understood as

\footnotetext{
${ }^{9}$ That matching succeeds between the discourse sisters $S_{1}$ and $S_{4}$ in (33) is shown in (34) (see also footnote 3). For (32), we need Büring's (1997) analysis of Topic accent, building on Rooth's framework. The relevant Topic matching condition is stated in (35) and applied to our example in (36):

(34) $\left.\left.\llbracket[\text { Did the students answer the survey? }]_{S 1}\right]\right] \subset \mathrm{F}\left([\text { they DID (answer the survey) }]_{S 4}\right)=\{$ they answered the survey, they didn't answer the survey\}

(35) Given a question answer sequence $\mathrm{Q} A, \llbracket Q \rrbracket$ must be an element of $\mathrm{T}(\mathrm{A})$, where $\mathrm{T}(\mathrm{A})$ is the set of the focus values $\mathrm{F}(\mathrm{A})$ resulting from substituting the Topic-accented element with some other element of the same type.

(36) $\left.\quad\left[[\text { Did the students answer the survey? }]_{S 1}\right]\right] \in$ $\mathrm{T}\left(\left[[\text { Everyone who received the FORMS }]_{\text {Topic }} \text { DID (answer the survey) }\right]_{S 4}\right)=$ $\{\{$ The students answered the survey, the students didn't answer the survey $\},\{$ the students in my class answered the survey, the students in my class didn't answer the survey\}, \{the students that received the forms answered the survey, the students that received the form didn't answer the survey $\}, \ldots\}$
} 
being $\left\{w^{\prime}\right.$ : it rains in $\left.w^{\prime}\right\}$. That is, semantically, the higher clauses $\mathrm{S}_{0}$ and $\mathrm{S}_{2}$ match. And, since $\mathrm{S}_{0}$ is the local c-commander of $\mathrm{S}_{2}$, matching occurs with the appropriate discourse relation.

(38) [If it rains, [ John will come home $\left.]_{S 1}\right]_{S 0}$. [ If $\mathrm{C}_{\left\{w^{\prime} \text { : it rains in } w^{\prime}\right\}}$, [Peter might (come home) $\left.]_{S 3}\right]_{S 2}$, too.

Matching is also done at the top level in the following variant, where not only the subjects but the content of the restrictor sets contrast with each other:

(39) [If it rains, [ John might come home $\left.]_{S 1}\right]_{S 0}$. [ [ Peter will (come home) $]_{S 3}$ no matter what $]_{S 2}$.

\subsection{Inferencing}

In Rooth's original exposition of the Matching Condition of VPE (Rooth, 1992a), he argued that Matching must have access to inferred antecedents. That is, his condition, repeated below, allows for the antecedent clause A to denote or to contextually imply a member of $\mathrm{F}(E)$. Matching through contextual implication was illustrated above with example (11).

(40) Matching Condition:

Ellipsis requires that there be some phrase E containing the ellipsis and some antecedent phrase $\mathrm{A}$ in the discourse, such that $\llbracket A \rrbracket$ is or contextually implies a member of $\mathrm{F}(E)$.

Once we take inferencing into account, some potential violations of the Discourse Condition are explained away. Take the following example (due to an anonymous reviewer):

(41) [[Agnes said she would come $]_{S 1}$ after [John left $\left.]_{S 2}\right]_{S 0}$.

But [[he hasn't $]_{S 3}$, so [she must not be here yet $\left.]_{S 4}\right]_{S 5}$.

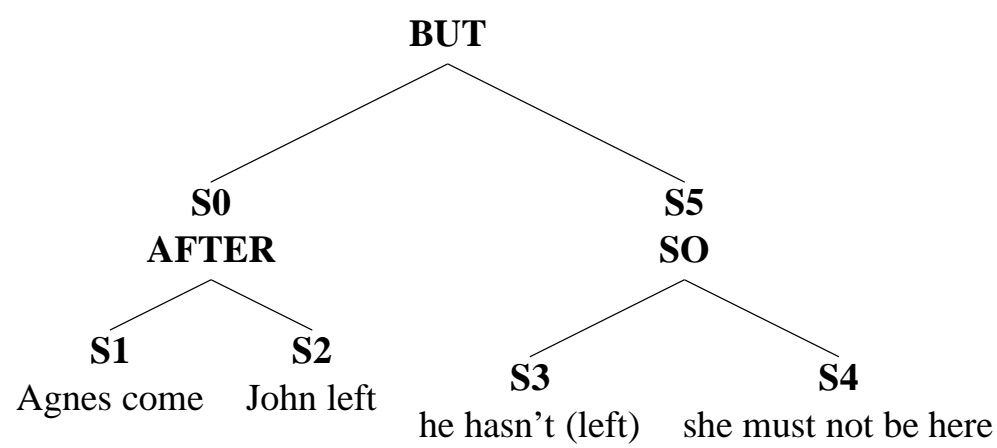

We see that the ellipsis site in $S_{3}$ can be resolved to the VP in $S_{2}$. The Discourse Condition does not allow for $S_{2}$ to be taken as the matching A of $S_{3}$ directly, since local c-command does not obtain between the two. But we can perform matching at a higher level between the sisters $S_{0}$ and $\mathrm{S}_{5}$ by using some inferencing. Let us see this in two steps. First, note that the A-clause $\mathrm{S}_{0}$ in (42a) implies (by some sort of Modus Tollens) the proposition in (42b). This proposition, in turn, implies the proposition in (42c), since " $x$ has not come" implies " $x$ is not here".

(42) a. $\mathrm{S}_{0}$ : Agnes said she would come after John left.

b. Proposition “that, if John hasn't left, Agnes must (according to Agnes's forecast) not have come yet".

c. Proposition "that, if John hasn't left, Agnes must (according to Agnes's forecast) not be here yet". 
Second, the final proposition (42c) "that, if John hasn't left, Agnes must (according to Agnes's forecast) not be here yet" matches $S_{5}$. To see this, take a discourse where this proposition is directly expressed, as in (45). It is clear that the higher sentences $S_{0}$ and $S_{5}$ express the consequence relation between the two same propositions "that John hasn't left" and "that Agnes is not here yet". The only difference is that $\mathrm{S}_{0}$ merely states this consequence relation (using if-then), whereas $\mathrm{S}_{5}$ expresses this consequence relation (using so) and furthermore emphazises the truth of the proposition "John hasn't left" in the actual world by focusing $H A S N{ }^{\prime} T .{ }^{10}$ In sum, $\mathrm{S}_{0}$ matches $\mathrm{S}_{5}$.

(45) [If [John hasn't left $]_{S 1}$, [Agnes must not be here yet $\left.]_{S 2}\right]_{S 0}$.

$\left.\left[[\text { He hasn't }]_{S 3} \text {, so [she must not be here yet }\right]_{S 4}\right]_{S 5}$.

Another example where inferencing explains a prima facie Discourse Condition violation is (46) (due to Satoshi Tomioka, p.c.).

(46) When [ [Bill got healthy] $\mathrm{S}_{1}$ after [he quit smoking] $\left.\mathrm{S}_{2}\right] \mathrm{S}_{0}$, [his brother did (quit smoking / got healthy after he quit smoking) as well] $\mathrm{S}_{3}$.

As in the prior example, the ellipsis in (46) can be resolved to the VP quit smoking of the embedded $S_{2}$, despite the fact that $S_{2}$ does not c-command the ellipsis clause $S_{3}$. However, we note that the elided VP gives rise to the interpretation "his brother quit smoking in order to get healthy". Furthermore, there is a natural inference from the A clause, Bill got healthy after he quit smoking, to the conclusion Bill got healthy in order to quit smoking. This inferred clause is indeed an element of the alternative set $\{x$ quit smoking in order to get healthy .

\subsection{Summary of section 3}

To sum up section 3, we have shown that the selection of an antecedent clause A for a clause E containing an ellipsis site is subject to discourse constraints. The data presented here can be captured if the Discourse Condition requires that the matching A-clause locally c-command the E-clause in the discourse tree. This condition leaves open the possibility that the E-clause be the minimal clause containing the ellipsis or that it be a higher one. The proposal also takes into account implicit material independently motivated for the interpreation of modals. Finally, the proposed analysis inherits the resource to contextual inferencing from Rooth's original matching condition.

In the following sections, we will see how the proposed Discourse Condition also has an effect on possible readings of pronouns (section 4) and on preferred scope readings (section 5).

\footnotetext{
${ }^{10}$ This is a use of auxiliary stress not as polarity Focus but as so-called VERUM Focus. See section 5.2 for discussion of this distinction. Roughly, $S_{0}$ in (45) conveys the proposition in (43), $S_{5}$ conveys the proposition in (44), and focal stress on $H A S N^{\prime} T$ indicates contrast between the epistemic certainty conveyed in $\mathrm{S}_{5}$ and the epistemic possibility conveyed in $\mathrm{S}_{0}$ :
}

"There is a consequence relation between John not leaving and Agnes not being here. It is (epistemically) possible that John has not left."

(44) "There is a consequence relation between John not leaving and Agnes not being here. It is (epistemically) certain that John has not left." 


\section{Possible Readings: The Many-Clause Puzzle}

\subsection{The Standard Many-Clause Puzzle}

We turn now to a well-known type of example, dubbed the "many-clause puzzle" by (Fiengo and May, 1994), and originally due to (Dahl, 1974).

(47) John revised his paper, and Bill did too, although the teacher didn't.

(48) [John revised his paper $]_{S 0}$, and

$\left[[\text { Bill did (revise his paper) }]_{S 2}\right.$ too, although

[the teacher didn't (revise his paper) $\left.]_{S 3}\right]_{S 1}$.

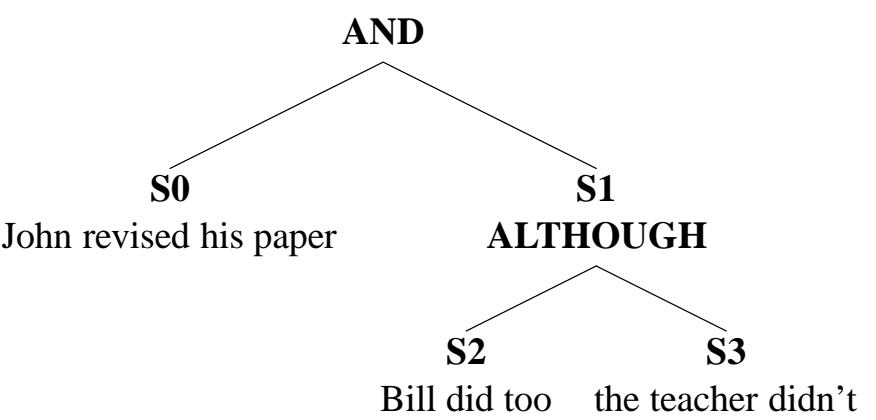

Note that there are two ellipsis clauses, $S_{2}$ and $S_{3}$. As observed by Dahl, there are three possible readings. First, there is the across the board strict reading, where John, Bill and the teacher all revised John's paper. Second, there is the across the board sloppy reading, where John, Bill and the teacher all revised their own paper. Third, there is a mixed reading, in which Bill revised Bill's paper (sloppy), although the teacher revised Bill's paper (strict). Other mixed readings are not possible. Thus of five potential readings, displayed below, only 1-3 are permitted.

Readings: 1. JJJ 2. JBT 3. JBB 4. *JJT 5. *JBJ

Below, we show how readings 1-3 are correctly permitted in our approach, whereas readings 4-5 are ruled out. As discussed in Section 2.2, we assume that a sloppy reading involves NP raising of the "controller" or antecedent for the sloppy pronoun in the E-clause.

1. (JJJ) All strict: $\left[\left[S_{0}\right]\right] \in F\left(S_{2}\right), \llbracket\left[S_{2} \rrbracket \in F\left(S_{3}\right)\right.$. $\mathrm{F}\left(\mathrm{S}_{2}\right)=\mathrm{F}\left(\mathrm{S}_{3}\right)=\{x$ revised John's paper $\}$

2. (JBT) All sloppy: $\llbracket\left[S_{0} \rrbracket \in F\left(S_{2}\right), \llbracket S_{2} \rrbracket \in F\left(S_{3}\right)\right.$. $\mathrm{F}\left(\mathrm{S}_{2}\right)=\mathrm{F}\left(\mathrm{S}_{3}\right)=\{x$ revised $x$ 's paper $\}$

3. (JBB) Sloppy/Strict:

$\left.\llbracket[\text { John revised John's paper }]_{S 0} \rrbracket \in \mathrm{F}(\text { BILL } \lambda x \cdot x \text { revised } x \text { 's paper }]_{S 2}\right)=\{x$ revised $x$ 's paper $\}$

$\llbracket[\text { Bill revised Bill's paper }]_{S 2} \rrbracket \in \mathrm{F}[\text { the TEACHER revised Bill's paper }]_{S 3}=\{x$ revised Bill's paper\}

4. *(JJT)

$\left.\left.\llbracket[\text { John revised John's paper }]_{S 0}\right]\right] \in \mathrm{F}\left([\text { BILL revised John's paper }]_{S 2}\right)=\{x$ revised John's paper $\}$

$\left.\llbracket[\text { Bill revised John's paper }]_{S 2} \rrbracket \notin \mathrm{F}(\text { [the TEACHER } \lambda x \cdot x \text { revised } x \text { 's paper }]_{S 3}\right)=\{x$ revised $x$ 's paper $\}$ 
5. *(JBJ)

$\left.\left[[\text { John revised John's paper }]_{S 0}\right]\right] \in \mathrm{F}\left([\mathrm{BILL} \lambda x . x \text { revised } x \text { 's paper }]_{S 2}\right)=\{x$ revised $x$ 's paper $\}$

$\left.\left[[\text { Bill revised Bill's paper }]_{S 2}\right]\right] \notin \mathrm{F}\left([\text { the TEACHER revised John's paper }]_{S 3}\right)=\{x$ revised John's paper \}

It is pointed out by (Fiengo and May, 1994) that Reading 5 (JBJ) is incorrectly permitted by the approach of (Dalrymple et al., 1991), since it allows that matching to relate the clause $S_{3}$ with clause $S_{1}$. The same criticism applies to Rooth's matching approach if deployed of the Discourse Condition, as we see below:

$\llbracket[\text { John revised John's paper }]_{S 1} \rrbracket \in \mathrm{F}\left([\mathrm{BILL} \lambda \mathrm{x} . \mathrm{x} \text { revised } \mathrm{x} \text { 's paper }]_{S 2}\right)=\{x$ revised $x$ 's paper \}

$\llbracket[\text { John revised John's paper }]_{S 1} \rrbracket \in \mathrm{F}\left([\text { the TEACHER revised John's paper }]_{S 3}\right)=\{x$ revised John's paper\}

This shows clearly that discourse relations play a crucial role in constraining available readings. Here, we don't allow match $\left(\mathrm{S}_{3}, \mathrm{~S}_{0}\right)$ because $\mathrm{S}_{0}$ does not locally c-command $\mathrm{S}_{3}$, because a closer c-commander of $S_{3}-$ namely, $S_{2}-$ appears between $S_{0}$ and $S_{3}$.

\subsection{A Variant of the Many-Clause Puzzle}

We turn now to a variant of the Many-Clause Puzzle, which further illustrates the interaction of discourse structure with the selection of available readings.

(49) John revised his paper BEFORE Bill did, but AFTER the teacher did.

(50) $\quad[\text { John revised his paper }]_{S 1}$ BEFORE

[Bill did (revise his paper) $\left.]_{S 2}\right]_{S 0}$, but [AFTER

[the teacher did (revise his paper) $\left.]_{S 3}\right]_{S 4}$.

Note that here, clause $S_{1}$ and $S_{2}$ are related by BEFORE, and $S_{1}$ and $S_{3}$ are related by AFTER, as shown in Figure 2. Furthermore, there is symmetrical focus on BEFORE and AFTER. This requires Match in both directions between the higher clauses $S_{0}$ and $S_{4}$, independently of ellipsis.

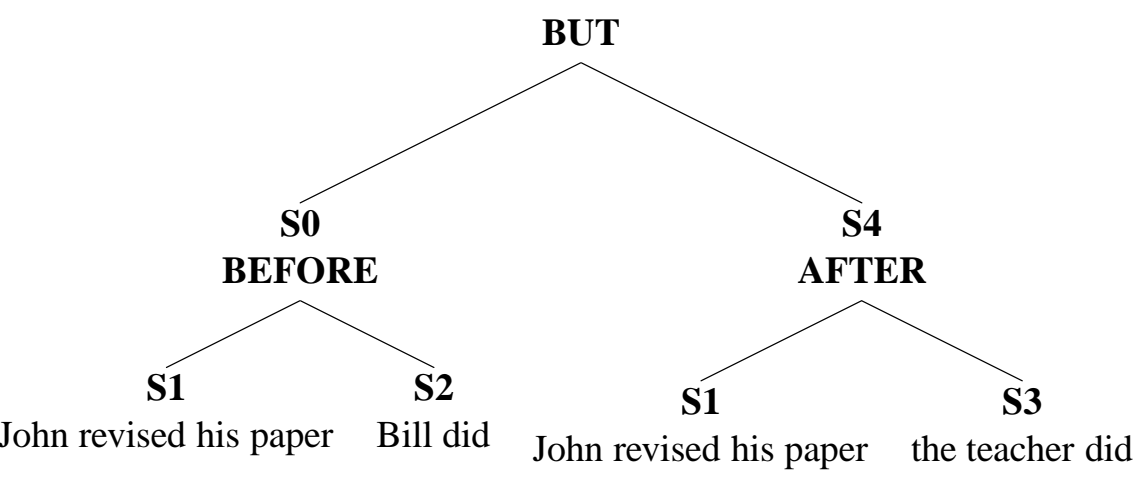

Because of the differences in discourse and focus structure, only Readings 1 and 2 are possible here:

Readings: 1. JJJ 2. JBT 3. *JBB 4. *JJT 5. *JBJ 
We examine each reading in turn. The strict-strict reading $\mathrm{JJJ}$ is possible because both ellipsis sites can find a containing E-clause that matches its discourse sister: $S_{1}$ and $S_{2}$ match, and $S_{1}$ and $\mathrm{S}_{3}$ match.

1. (JJJ) All strict:

$\llbracket\left[\mathrm{John}_{1} \text { revised his }{ }_{1} \text { paper }\right]_{S 1} \rrbracket \in \mathrm{F}\left(\left[\mathrm{BILL}_{2} \text { revised his }{ }_{1} \text { paper }\right]_{S 2}\right)$.

$\llbracket\left[\mathrm{John}_{1} \text { revised his }_{1} \text { paper }\right]_{S 1} \rrbracket \in \mathrm{F}\left(\left[\text { the } \mathrm{TEACHER}_{3} \text { revised his }{ }_{1} \text { paper }\right]_{S 3}\right)$

For the sloppy-sloppy reading JBT, the subjects Bill and the teacher are raised, and the pronouns are lambda-bound variables. Just as in reading 1 , we can see that both ellipsis sites can find a containing E-clause that matches its discourse sister: $S_{1}$ and $S_{2}$ match, and $S_{1}$ and $S_{3}$ match.

2 (JBT) All sloppy:

$\llbracket\left[\mathrm{John}_{1} \lambda \text { x.X revised } x \text { 's paper }\right]_{S 1} \rrbracket \in \mathrm{F}\left(\left[\mathrm{Bill}_{2} \operatorname{did}(\lambda x . x \text { revise } x \text { 's paper })\right]_{S 2}\right)=\{x$ revised $x$ 's paper\}.

$\left[\left[\mathrm{John}_{1} \lambda \text { x.x revised } x \text { 's paper }\right]_{S 1} \rrbracket \in \mathrm{F}\left([\text { the TEACHER } 3 \text { } \lambda \text { x.X revised } x \text { 's paper }]_{S 3}\right)=\{x\right.$ revised $x$ 's paper\}

We turn now to the sloppy-strict reading JBB, which is now ruled out, while it was permitted with example (48). For the first ellipsis site, the Discourse Condition is fulfilled, since the sisters $S_{1}$ and $S_{2}$ match, as shown below. The Discourse Condition is also met for the second ellipsis site if we choose matching at higher levels: if we take the E-clause to be $\mathrm{S}_{4}$, then its sister $\mathrm{S}_{0}$ 's denotation belongs to $\mathrm{F}\left(\mathrm{S}_{4}\right)$ and the Discourse Condition is satisfied, as indicated below. However, the reading is ruled out as the result of two factors. First, $S_{2}$ must involve lambda binding of the pronoun his, so that it represents the alternative set $\{x$ revised $x$ 's paper $\}$. Otherwise, the first clause $S_{1}$, "John revised John's paper" would not match $S_{2}$. Second, given that we have symmetrical focus on BEFORE and AFTER, the clause $S_{4}$ must be an element of the focus value of $S_{0}$ as well, to license the focus on BEFORE. But this fails, because the $S_{4}$ contains the clause $S_{3}$ ("the teacher revised Bill's paper"), and this clause cannot match with $S_{2}$, whose alternative set we saw is $\{x$ revised $x$ 's paper $\}$.

$3 *(\mathrm{JBB})$ :

$\llbracket \mathrm{S}_{1} \rrbracket \in \mathrm{F}\left(\mathrm{S}_{2}\right)$ :

$\llbracket\left[\mathrm{John}_{1} \text { revised his }{ }_{1} \text { paper }\right]_{S 1} \rrbracket \in \mathrm{F}\left(\left[\mathrm{Bill}_{2} \operatorname{did}(\lambda x . x \text { revise } x \text { 's paper })\right]_{S 2}\right)$.

$\llbracket \mathrm{S}_{0} \rrbracket \in \mathrm{F}(\mathrm{S} 4)$ :

$\llbracket\left[\mathrm{John}_{1} \text { revised his } 1 \text { paper before } \mathrm{Bill}_{2} \mathrm{did}(\lambda x . x \text { revise } x \text { 's paper })\right]_{S 0} \rrbracket \in$

$\left.\mathrm{F}\left(\left[\mathrm{John}_{1} \text { revised his }_{1} \text { paper AFTER the TEACHER } 3 \text { did (revise his } 2 \text { paper }\right)\right]_{S 4}\right)=$ \{John revised John's paper $\mathrm{R} x$ revised Bill's paper $\}$

But $[[\mathrm{S} 4]] \notin \mathrm{F}\left(S_{0}\right)$, since:

$\llbracket\left[\mathrm{John}_{1} \text { revised his }{ }_{1} \text { paper after the teacher } 3 \text { did (revise his } 2 \text { paper) }\right]_{S 4} \rrbracket \notin$

$\mathrm{F}\left(\left[\mathrm{John}_{1} \text { revised his } 1 \text { paper BEFORE BILL } 2 \text { did }(\lambda x . x \text { revise } x \text { 's paper })\right]_{S 0}\right)=$ $\{$ John revised John's paper $\mathrm{R} x$ revised x's paper $\}$

Finally, the impossible readings JJT and JBJ are ruled out, independently of ellipsis itself, because the focus on AFTER requires that $\left[\mathrm{S}_{0} \rrbracket\right.$ belong to $\mathrm{F}\left(\mathrm{S}_{4}\right)$, but this matching does not succeed:

$4 *(\mathrm{JJT}): S_{0} \notin \mathrm{F}\left(S_{4}\right)$, since:

【[ $\left[\mathrm{John}_{1} \text { revised his }{ }_{1} \text { paper before } \text { Bill }_{2} \text { did (revise his } 1 \text { paper) }\right]_{S 0} \rrbracket \notin$

$\mathrm{F}\left(\left[\mathrm{John}_{1} \text { revised his } 1 \text { paper AFTER the TEACHER } 3 \lambda x . x \text { revised } x \text { 's paper }\right]_{S 4}\right)=$

\{John revised John's paper $R x$ revised $x$ 's paper\}. 
$5 *(\mathrm{JBJ})$ :

$S_{0} \notin \mathrm{F}\left(S_{4}\right)$, since:

$\llbracket\left[\mathrm{John}_{1} \text { revise his } 1 \text { paper before } \mathrm{Bill}_{2}(\lambda x . x \text { revise } x \text { 's paper })\right]_{S 0} \rrbracket \notin$

$\mathrm{F}\left(\left[\mathrm{John}_{1} \text { revised his }_{1} \text { paper AFTER the TEACHER } \text { Tevised his }_{1} \text { paper }\right]_{S 4}\right)=$

\{John revised John's paper $R x$ revised John's paper\}.

In sum, discourse structure constrains the application of the Matching Condition and hence the availability of pronominal readings in ellipsis. Changing the discourse structure results in changes in the possible readings, in the way predicted by the Discourse Condition.

\section{Possible Readings: Scope and Ellipsis Size in Antecedent-Contained Deletion}

\subsection{Preferences in ACD}

Consider the following example of Antecedent-Contained Deletion (ACD) (Sag, 1976):

(51) The teacher wanted Mary to read everything Sue didn't (/did).

The quantified NP headed by everything can in principle take scope over or under wanted, and the ellipsis site can be resolved to read (small ellipsis) or to wanted Mary to read (large ellipsis). This gives the following four logical possibilities:

(52) Reading a: Wide scope of every, large ellipsis.

For every x: if Sue didn't want Mary to read x, the teacher wanted Mary to read x.

SCENARIO: The teacher and Sue had completely different desires: for every particular x that Sue didn't want Mary to read, the teacher wanted Mary to read x.

(53) Reading b: Narrow scope of every, small ellipsis.

The teacher wanted this: that, for every x, if Sue didn't read x, then Mary reads x.

SCENARIO: The teacher didn't know what Sue read or didn't read. The teacher simply wanted all the material to be read by one of the two. That is, the teacher just wanted for Mary to read whatever Sue didn't read.

(54) \% Reading c: Wide scope of every, small ellipsis.

For every x: if Sue didn't read x, the teacher wanted Mary to read x.

SCENARIO: Unbeknownst to the teacher, Sue didn't read Sinn und Bedeutung, Tractatus and $P T Q$. It turns out that, for each of those $\mathrm{x}$, the teacher coincidentally wanted Mary to read $\mathrm{x}$.

(55) * Reading d: Narrow scope of every, large ellipsis.

The teacher wanted this: that, for every $\mathrm{x}$, if Sue didn't want Mary to read $\mathrm{x}$, then Mary reads $\mathrm{x}$.

As first observed in (Sag, 1976), reading (d) gives rise to an impossible structure and is in fact ruled out by many well-known accounts (see (Fiengo and May, 1994) for discussion and references). The remaining readings (a), (b) and (c) result in well-formed syntactic representations and are expected to be available. We note, however, that there is a preference for readings (a)(b) over reading (c): while the readings (a)-(b) of (51) are easily available, reading (c) is hard to obtain in most contexts. Example (56) illustrates the contrast between readings (a)-(b) and reading (c) as well, perhaps more sharply:

(56) Pat refused to read everything John did.

(57) Reading a: Wide scope of every, large ellipsis.

For every $\mathrm{x}$ : if John refused to read $\mathrm{x}$, Pat refused to read $\mathrm{x}$. 
Reading b: Narrow scope of every, small ellipsis.

Pat refused to do this: to read every x that John read.

$\%$ Reading c: Wide scope of every, small ellipsis.

For every $\mathrm{x}$ : if John read $\mathrm{x}$, Pat refused to read $\mathrm{x}$.

We claim that reading (c) is degraded compared to (a) and (b), and that it is only available if the context primes for it, as in (60). Here, the opening of the discourse Pat won't get her wish seems to make salient the contrast between Pat's desires and the actual facts. This makes reading (c) easily available. ${ }^{11}$

(60) Pat won't get her wish... She wants you to like everybody you won't (like).

Reading c: Wide scope of everybody, small ellipsis:

For every $\mathrm{x}$ : if you won't (like $\mathrm{x}$ ), then she wants you to like $\mathrm{x}$.

The goal of this section is to show that reading (c) is dispreferred because of the Discourse Condition, together with an independently motivated economy factor that we call Focus Economy. We will show that focused auxiliaries can give rise to simple polarity-based alternative sets, but that they can also give rise to more complex VERUM-based alternative sets. Our Focus Economy principle dictates that there is a preference for the simpler polarity-based alternative sets. Together with Focus Economy, the Discourse Condition provides an account of the above preference for (a)-(b) over (c).

\subsection{Auxiliaries and Alternative Sets}

For most examples of focused auxiliaries, the focus set of alternatives specified in (61) is generally assumed. In other words, the stress on DID or DIDn't is usually taken to focus the plain positive or negative polarity: e.g., DID $p$ means roughly $p$ as opposed to $\neg p$. This is the default set of alternatives for a focused auxiliary, and it is enough to fulfill the matching condition in simple sentences like (62).

$$
\mathrm{F}\left(\text { DID }_{P o l} p\right)=\mathrm{F}\left(\text { DIDn't }_{P o l} p\right)=\{p, \neg p\}
$$

$$
\text { John won a race, but CHRIS DIDn't. }
$$

But this is not the only use of focal accent on auxiliaries. Independently of ellipsis, (Höhle, 1992) and (Romero and Han, 2002) (among others) describe a use of auxiliary focus where stress emphasizes (or contrasts) not the polarity itself, but a predicate or operator VERUM meaning roughly "it is true that" or "it is for sure true that". ${ }^{12}$ This use of auxiliary focus is illustrated in the examples (64), (65) and (66). ${ }^{13}$ It is clear that, in (64), focus on DID does not signal contrast with the polarity of the previous embedded clause [she finished her work on time], since the polarity of this clause and the stressed polarity of DID are both positive. Instead, auxiliary stress here marks contrast between the operator VERUM (="it is for sure true that") and the attitude expressed in the preceding clause by I hope ("it is hoped that"). In a similar fashion, in (65), the clause [she made the silly claim that p] conveys the proposition "that it is doubted that $p$ ", and auxiliary stress intuitively marks contrast between "it is doubted that" and "it is for sure

\footnotetext{
${ }^{11}$ We will come back to the effect of the context in (60) in subsection 5.3, once our analysis is presented.

${ }^{12}$ (Romero and Han, 2002) define VERUM as the conversational epistemic operator in (63):

$$
\begin{aligned}
& \left.\llbracket V E R U M_{i} \rrbracket^{g x / i}=\llbracket \text { really }_{i}\right]^{g x / i}= \\
& \lambda p_{<s, t>} \lambda w . \forall w^{\prime} \in E i_{x}(w)\left[\forall w^{\prime \prime} \in \operatorname{Bou}_{x}\left(w^{\prime}\right)\left[p \in C G_{w^{\prime \prime}}\right]\right]
\end{aligned}
$$

${ }^{13}$ Example (65) is the English version of (Höhle, 1992)'s example (2).
} 
true that". Finally, in (66), VERUM ("it is for sure true that") contrasts with the denotation of the modal may ("it is possible that").

(64) A: I hope she finished her work on time.

S: She DID finish it on time.

LF: [VERUM $F$ [ she finished it on time ] ]

(65) A: I asked Hanna what Karl was doing, and she made the silly claim that he is writing a script.

S: (It's true.) He IS writing a script.

LF: [ $\operatorname{VERUM}_{F}$ [ he is writing a script ] ]

(66) A: Sophia may be asleep.

S: She IS asleep.

The focus set of alternatives of this modal-like operator VERUM is sketched in (67): 14

$\mathrm{F}\left(\mathrm{DID}_{\text {Verum }} p\right)=\mathrm{F}\left(\mathrm{DIDn}_{\text {Verum }} p\right)=$

$\{$ it is for sure true that $p$, it is possible that $p$, it is hoped that $p$, it is doubted that $p$, it is wanted that $p$, it is expected that $p, \ldots$, John expects that $p$, John hopes that $p$, Sam expects that $p, \ldots$ it is for sure true that $\neg p$, it is possible that $\neg p$, it is hoped that $\neg p$, it is doubted that $\neg p$, it is wanted that $\neg p$, it is expected that $\neg p, \ldots$, John expects that $\neg p$, John hopes that $\neg p$, Sam expects that $\neg p, \ldots\}$

This VERUM-set of alternatives is also operative in ellipsis. Take the examples (68)-(69). Matching is performed between the discourse sisters $S_{0}$ and $S_{2}$, following the Discourse Condition. In both sentences, the denotation of $S_{0}$ belongs to the VERUM set of alternatives of $S_{2}$. Matching is, hence, satisfied in accordance with the Discourse Condition:

[ Sue expected John to win $]_{S 0}$, and [he DID $]_{S 2}$.

$\left[[\text { [Sue expected John to win }]_{S 0} \rrbracket \in \mathrm{F}([\right.$ he DID win] $)=$

\{it is for sure true that John won, it is possible that John won, ... Sue wanted that John won, Sue expected that John won, ...

[ John wanted [to go to Rome $]_{S 0}$, but [he DIDN'T] $]_{S 2}$.

$\left[[\text { John wanted to go to Rome }]_{S 0}\right] \in \mathrm{F}([$ he DIDN'T go to Rome $])=$

\{it is for sure true that John did not go to Rome, it is for sure true that John went to Rome, it was wanted that John go to Rome, it was wanted that John didn't go to Rome,...

Both the polarity-based alternative set and the VERUM-based set follow Rooth's requirement that the alternatives be of the same semantic type (see (4b) above). Our proposal is also consistent with the proposal from (Heim, 1997)[210] that alternative sets be restricted to natural alternatives; in our view, polarity functions like $\lambda p \lambda w \cdot p(w)=1$ and $\lambda p \lambda w \cdot p(w)=0$ form a natural class and modal functions introducing quantification over possible worlds form another.

Once these two alternative sets are generated for focused DID and DIDn't, the question arises whether they are equally available. We propose that the simpler polarity-based set is the default one and that the VERUM-based set, which involves positing a lexically unrealized operator and a more complicated alternative set, is dispreferred in neutral scenarios where no contextual cues prime it. This can be seen in (70) and (71). Take (70), for example. We have in principle the following two options: (i) PAT contrasts with Mary, DIDn't is plain polarity focus and the

\footnotetext{
14(Romero and Han, 2002), building on (Höhle, 1992), discuss a scope ambiguity between negation and VERUM in focused negative auxiliaries: DIDn't $p$ is ambiguous between the LF [VERUM not $p$ ] and the LF [not VERUM $p]$. To be faithful to this ambiguity, we would need two sets of alternatives for a focused negative auxiliary. For simplicity, we only give one set of alternatives in the text, sufficient for the examples at hand.
} 
ellipsis is resolved to want Sue to attend the meeting; or (ii) PAT contrasts with Sue, DIDN'T is VERUM focus and the ellipsis resolves to attend the meeting. In the absence of any cues priming the latter VERUM option, the former polarity option is preferred. In the same fashion, in (71), the ellipsis resolution to expect Amy to like it is preferred over the resolution to like it because the former uses the polarity-based alternative set and the latter necessitates the VERUM-based set.

(70) Guess what! I found out two things concerning yesterday's meeting: that Mary wanted Sue to attend the meeting and that PAT DIDn't (want Sue to attend the meeting / ??attend the meeting)

(71) A: Did you hear any gossip concerning this painting?

B: Only this: John expects Amy to like it and SUE DOESn't (expect Amy to like it / ??like it).

We state the asymmetrical status of the two alternative sets in the following Focus Economy condition:

Focus Economy (for auxiliary stress):

The interpretation of auxiliary stress as polarity focus is more economical than its VERUM interpretation. That is, ceteris paribus and in the absence of contextual bias, polarity focus is preferred over VERUM focus when an auxiliary is stressed.

With these two sets of alternatives for DID/DIDn't and with the Focus Economy principle delimiting their distribution, we are ready to return to ACD and its readings. ${ }^{15} 16$

\footnotetext{
${ }^{15}$ Although we have restricted ourselves to non-modal auxiliaries like DID and DIDn't in the text, focal stress on modal auxiliaries can also be understood in two ways: as focusing the bare polarity, as in (73), or as focusing the modal itself, as in (74). Again, in neutral scenarios, the polarity-base alternative set is preferred over the modal-based set, as (75) suggests:
} John should go to the gathering, but BILL SHOULDn't. John doesn't want to go to the gathering, but he SHOULD.

Nobody told John to go to the gathering. BILL SHOULD (tell John to go to the gathering / ??go to the gathering).

16 The examples seen in this section contained phonological stress on the auxiliary at issue. However, a problem remains in examples like (76), where the subject of the E-clause is pronounced with focal stress but the auxiliary does not seem to bear stress. For matching to obtain between $S_{0}$ and $S_{2}$, we would need to invoke the VERUM set of alternatives of did even though did is not phonologically focused. This is a topic that merits further investigation. One possibility is that there is an additional accent on did, which is somewhat difficult to perceive. Another possibility is that VP ellipsis creates a tendency for semantic focus to fall on the auxiliary verb. In any case, this question arises independently of the Discourse Condition and the VERUM alternatives proposed in this paper: even if we dropped our Discourse Condition, neither matching between $S_{1}$ and $S_{2}$ nor matching between $S_{0}$ and $S_{2}$ succeeds in (77) unless the unstressed auxiliary should is somehow understood as semantically focused, as shown below:

(76) [Sue expected [John to win $\left.]_{S 1}\right]_{S 0}$, but $[\text { BILL did }]_{S 2}$.

$\llbracket[\text { Sue expected John to win }]_{S 0} \rrbracket \notin \mathrm{F}([\mathrm{BILL} \operatorname{did}$ (win) $])$

$\llbracket[\text { Sue expected John to win }]_{S 0} \rrbracket \in \mathrm{F}\left(\left[\mathrm{BILL} \mathrm{DID}_{\text {Verum }}\right.\right.$ (win)])

(77) [Mary wants [John to pick up the students this time $\left.]_{S 1}\right]_{S 0}$, though [BILL should (pick up the students this time) $]_{S 2}$

【[ John to pick up the students $]_{S 1} \rrbracket \notin \mathrm{F}\left([\mathrm{BILL} \text { should (pick up the students) }]_{S 2}\right)$

$\llbracket[\text { John to pick up the students }]_{S 1} \rrbracket \in \mathrm{F}\left([\mathrm{BILL} \text { SHOULD (pick up the students) }]_{S 2}\right.$ )

【 [Mary wants John to pick up the students $]_{S 0} \rrbracket \quad \notin \quad \mathrm{F}\left([\mathrm{BILL} \text { should (pick up the students) }]_{S 2}\right.$

$\llbracket[\text { Mary wants John to pick up the students }]_{S 0} \rrbracket \in \mathrm{F}\left([\text { BILL SHOULD (pick up the students) }]_{S 2}\right.$ 


\subsection{Antecedent-Contained Deletion}

We can now show why reading (c) is degraded, as compared with readings (a) and (b). We repeat our ACD example (51) here as (78):

(78) The teacher wanted Mary to read everything Sue didn't.

Reading (a) is derived as in (79). Wide scope of every determines that the discourse sister of the ellipsis clause $S_{2}$ is $S_{0}$, as shown in the tree below. $S_{0}$ matches $S_{2}$ without having to use the VERUM-based set of alternatives, since the basic polarity-based suffices, as stated in (80). Thus, reading (a) is easily available.

(79) Reading a: Wide scope of every, large ellipsis.

LF: Everything that [SUE DIDn't (want Mary to read t) $]_{S 2}$ [the teacher wanted $\left.[\text { Mary to read t }]_{S 1}\right]_{S 0}$

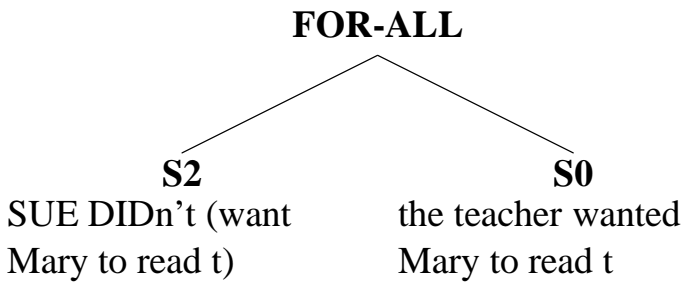

(80) $\left.[[\text { the teacher wanted Mary to read } \mathrm{t}]]_{S 0}\right] \in \mathrm{F}\left(\left[\right.\right.$ SUE DIDn't ${ }_{\text {Pol }}$ (want Mary to read t) $]_{S 2}$ )

In reading (b), the narrow scope of every yields the discourse tree under (81). This time, the matching A-clause for the E-clause $S_{2}$ has to be $S_{1}$. This matching can be satisfied by using the polarity-based set of alternatives, as in (82), and hence this reading is easily available:

(81) Reading b: Narrow scope of every, small ellipsis.

LF: The teacher wanted [ everything that [SUE DIDn't (read t) $\left.]_{S 2}[\text { Mary to read t }]_{S 1}\right]$

The teacher wanted
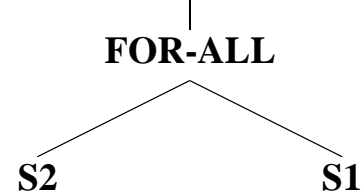

SUE DIDn't (read t) Mary to read t

$$
\left[\left[[\text { Mary to read } \mathrm{t}]_{S 1} \rrbracket \in \mathrm{F}\left(\left[\text { SUE DIDn't }{ }_{P o l}(\operatorname{read} \mathrm{t})\right]_{S 2}\right)\right.\right.
$$

Let us turn to reading (c). Wide scope of every results in attachment of $E$ to $S_{0}$ and the ellipsis is resolved to read $t$, as represented in the tree under (83). Matching between the discourse sisters $S_{0}$ and $S_{2}$ cannot be satisfied if we use the polarity-based set of alternatives; we need the VERUM-set to fulfill matching. This is shown in (84a-b):

(83) Reading c: \% Wide scope of every, small ellipsis.

LF: Everything that [ SUE DIDn't (read t) $]_{S 2}$ [the teacher wanted [Mary to read t $]_{S 1}$ ]$_{S 0}$ 


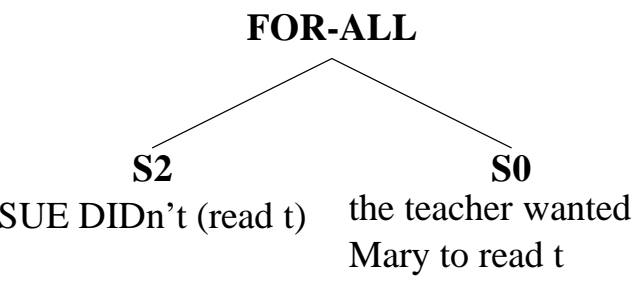

a. Polarity-based alternative set:

[the teacher wanted Mary to read $\mathrm{t}]_{S 0} \notin$ (nor implies a proposition in) $\mathrm{F}$ ([SUE $\left.\left.\operatorname{DID}_{P o l}(\mathrm{read} t)\right]_{S 2}\right)$, which equals $\{$ Sue read t, Sue didn't read t, Mary read t, Mary didn't read $t, \ldots\}$

b. VERUM-based alternative set:

$[\text { the teacher wanted Mary to read } \mathrm{t}]_{S 0} \in \mathrm{F}\left(\left[\operatorname{SUE} \operatorname{DID}_{\text {Verum }}(\text { read } \mathrm{t})\right]_{S 2}\right)=$

$\{$ it is true that Sue read $t$, it is true that Mary read $t, \ldots$, the teacher wanted that Sue read $t$, the teacher wanted that Mary read $t, \ldots\}$

This means that, because reading (c) necessarily involves the VERUM set of alternatives and readings (a) and (b) do not, reading (c) is less economical than readings (a) and (b). Hence, following Focus Economy, unless the context primes the VERUM interpretation, the VERUMbased alternative set and the reading (c) that depends on it are dispreferred.

It is crucial to note that Focus Economy (72) could not by itself derive this result. If we abandoned the Discourse Condition, the non-sister $S_{1}$ would be allowed to match $S_{2}$ in (85). But then the polarity interpretation of auxiliary focus would be sufficient and assumption (72) could not possibly make this reading dispreferred. This is shown in (86).

(85) [ The teacher wanted [Mary to read t $\left.]_{S 1}\right]_{S 0}$ everything [SUE DIDn't (read) $]_{S 2}$

(86) $\quad[\text { Mary to read } \mathrm{t}]_{S 1} \in \mathrm{F}([\mathrm{SUE} \operatorname{did}(\mathrm{read})])_{S 2}$.

Alternatively, one could try to couple the Focus Economy principle (72) with a new constraint instead of the Discourse Condition- that dictates preference for non-embedded VP antecedents. This new constraint would be able to rank reading (c) as hard for (85), but it would also predict the same difficulty for the wide scope - small ellipsis reading of (87), since the antecedent VP is equally embedded in both cases. This prediction is contrary to fact. If we take the Discourse Condition, instead, the aforementioned reading of (87) is correctly predicted to be perfectly available, since the discourse sisters $S_{0}$ and $S_{2}$ match without the resource to the VERUM set of alternatives. This is shown in (88):

(87) [ The teacher wanted [Mary to read $\left.\mathrm{t}]_{S 1}\right]_{S 0}$ everything $[\text { SUE wanted her to (read) }]_{S 2}$

(88) Reading c: Wide scope of every, small ellipsis:

LF: Everything that $\left.[\text { SUE wanted [Mary to }(\operatorname{read} t)]_{S 3}\right]_{S 2}[$ the teacher wanted [Mary to read $\left.]_{S 1}\right]_{S 0}$

$[\text { the teacher wanted Mary to read } \mathrm{t}]_{S 0} \in \mathrm{F}\left([\mathrm{SUE} \text { wanted Mary to }(\operatorname{read} \mathrm{t})]_{S 2}\right)$

Before concluding this section, let us briefly consider example (60), repeated below. We saw that here the context makes reading (c) easily available. Why? Note that what the beginning of the discourse Pat won't get her wish does is to make salient the conflict between desire and reality. That is, it makes salient two of the propositions in the VERUM set: "it is wanted that $p$ " and "it is for sure true that $\neg p$ ". Given this priming, the focal stress on WON'T is readily understood as VERUM-focus. Thus, in this case, the context overrides Focus Economy, which favors the polarity-set over the VERUM-set only in case there is no contextual bias. 
(89) Pat won't get her wish... She wants you to like everybody you won't (like).

Reading c: Wide scope of everybody, small ellipsis:

For every $\mathrm{x}$ : if you won't (like $\mathrm{x}$ ), then she wants you to like $\mathrm{x}$.

To sum up section 5, the Discourse Condition has an effect on the ranking of some possible readings over others in ACD. This condition, together with economy considerations favoring the polarity use of auxiliary stress over its VERUM use, can derive the dispreference for reading (c) (wide scope and small ellipsis) in neutral contexts. This effect is not captured by other ellipsis approaches in the literature that do not impose any discourse requirement on matching.

\section{Conclusions and further issues}

Before concluding this paper, we would like to consider a case involving symmetric focus. Recall that example (27), repeated below, is ungrammatical under ellipsis resolution to eat. But what happens if we add focus on John, as in (91)?

(90) If [Agnes arrived after [John ate $\left.]_{S 3}\right]_{S 1}$ then [Bill didn't $]_{S 2}$ * $*$ (eat)/ (arrive after John ate)

(91) If [Agnes arrived after $\left.[\mathrm{JOHN} \text { ate }]_{S 3}\right]_{S 1}$ then [BILL didn't $]_{S 2} . \%$ (eat)/ \%(arrive after John ate)

Judgments are unclear for (91). We suggest that this is because, under any possible resolution, there is a clash between matching and c-command. On the one hand, the focus on JOHN requires that ellipsis is resolved as eat (this way, the phrase [JOHN ate] contrasts with [BILL didn't eat]). But this leads to a violation of the local c-command discourse condition, since $\mathrm{S}_{3}$ is not c-command to $\mathrm{S}_{2}$. On the other hand, if ellipsis is resolved as arrive after John ate and c-command obtains, then the phrase [JOHN ate] is not matched, and, hence, it is infelicitous. Hence, the accenting in (91) may be marginal under any ellipsis resolution because there is no winning resolution candidate. Instead, on either resolution of the ellipsis, we obtain a violation.

To conclude, our basic claim is that discourse structure constrains the way in which ellipsis satisfies the matching or parallelism condition advocated for in the ellipsis literature. We have proposed a very simple way to capture this: the parallelism match must involve two clauses that are related by local c-command in the discourse tree. We have shown how this simple claim successfully captures facts about the selection of antecedent for ellipsis, and about the determination of possible readings with a given antecedent. We have also shown how our claim interacts with implicit semantic material and with inferred antecedents.

DANIEL HARDT

Dept. of Computational Linguistics

Copenhagen Business School

Denmark

dh@id.cbs.dk

MARIBEL ROMERO

Linguistics Department

610 Williams Hall

University of Pennsylvania

Philadelphia, PA 19104 USA 
romero@ling.upenn.edu

\section{References}

[Asher et al., 2001] Nicholas Asher, Daniel Hardt, and Joan Busquets. Discourse parallelism, ellipsis, and ambiguity. Journal of Semantics, 18(1), 2001.

[Asher, 1993] Nicholas Asher. Reference to Abstract Objects in English. Dordrecht, 1993.

[Büring, 1997] Daniel Büring. The Meaning of Topic and Focus - The 59th Street Bridge Accent. London: Routledge, 1997.

[Chung et al., 1995] S. Chung, W. Ladusaw, and J. McCloskey. Sluicing and logical form. Natural Language Semantics, 3:1-44, 1995.

[Dahl, 1974] Osten Dahl. How to open a sentence: abstraction in natural language. In Logical Grammar Reports 12. University of Gothenburg, Sweden, 1974.

[Dalrymple et al., 1991] Mary Dalrymple, Stuart Shieber, and Fernando Pereira. Ellipsis and higher-order unification. Linguistics and Philosophy, 14(4), August 1991.

[Fiengo and May, 1994] Robert Fiengo and Robert May. Indices and Identity. MIT Press, Cambridge, MA, 1994.

[Hardt, 1993] Daniel Hardt. Verb Phrase Ellipsis: Form, Meaning, and Processing. PhD thesis, University of Pennsylvania, 1993.

[Heim and Kratzer, 1998] Irene Heim and Angelika Kratzer. Semantics in Generative Grammar. Blackwell, Oxford, 1998.

[Heim, 1997] Irene Heim. Predicates or formulas? evidence from ellipsis. In Proceedings of the Seventh Conference on Semantics and Linguistic Theory, Palo Alto, CA, 1997.

[Hobbs, 1979] Jerry Hobbs. Coherence and coreference. Cognitive Science, 3:67-90, 1979.

[Höhle, 1992] T. Höhle. Ueber verum fokus in deutschen. Linguistische Berichte, 1992.

[Jacobson, 1992] Pauline Jacobson. Antecedent contained deletion in a variable-free semantics. In Proceedings of the Second Conference on Semantics and Linguistic Theory, Columbus, Ohio, 1992.

[Kehler, 2000] Andrew Kehler. Coherence and the resolution of ellipsis. Linguistics and Philosophy, 23(6):533-575, 2000.

[Kratzer, 1979] Angelika Kratzer. Conditional necessity and possibility. In R. Bauerle U. Egli and A. von Stechow, editors, In Semantics from different points of view, page 117147. Springer-Verlag, Berlin, 1979.

[Mann and Thompson, 1986] William Mann and Sandra Thompson. Relational propositions in discourse. Discourse Processes, 9(1):57-90, 1986.

[Marcu, 2000] Daniel Marcu. The Theory and Practice of Discourse Parsing and Summarization. The MIT Press, 2000.

[Merchant, 2001] Jason Merchant. The syntax of silence: Sluicing, islands, and identity in ellipsis. Oxford, 2001. 
[Prust et al., 1994] Hub Prust, Remko Scha, and Martin van den Berg. A discourse perspective on verb phrase anaphora. Linguistics and Philosophy, 17(3):261-327, 1994.

[Romero and Han, 2002] Maribel Romero and Chung-hye Han. Verum focus in negative yes/no questions. In Proceedings of Semantics and Linguistic Theory, volume 12, Ithaca, NY, 2002. CLC Publications.

[Romero, 1998] Maribel Romero. Focus and Reconstruction Effects in Wh-Phrases. PhD thesis, University of Massachusetts-Amherst, 1998.

[Rooth, 1985] Mats Rooth. Association with Focus. PhD thesis, University of MassachusettsAmherst, 1985.

[Rooth, 1992a] Mats Rooth. Ellipsis redundancy and reduction redundancy. In Proceedings of the Stuttgart Ellipsis Workshop, Stuttgart, Germany, 1992.

[Rooth, 1992b] Mats Rooth. A theory of focus interpretation. Natural Language Semantics, 1:75-116, 1992.

[Sag, 1976] Ivan A. Sag. Deletion and Logical Form. PhD thesis, Massachusetts Institute of Technology, 1976. (Published 1980 by Garland Publishing, New York).

[Schwarzschild, 1999] Roger Schwarzschild. Givenness, avoid f and other constraints on the placement of focus. Natural Language Semantics, 7(2):141-177, 1999.

[Tancredi, 1992] Christopher Tancredi. Deletion, Deaccenting and Presupposition. PhD thesis, Massachusetts Institute of Technology, 1992.

[von Fintel, 1994] Kai von Fintel. Restriction on Quantifier Domains. PhD thesis, University of Massachusetts-Amherst, 1994.

[Webber et al., 2001] B. Webber, M. Stone, A. Joshi, and A. Knott. Anaphora and discourse semantics. submitted, 2001. 